\title{
COMBINING COASTAL DESIGN-FLOOD ELEVATIONS AND SEA LEVEL RISE PROJECTIONS
}

\author{
James Houston $^{1}$
}

\begin{abstract}
Design-flood elevations with associated exceedance probabilities are often determined for coastal projects. Rising sea level introduces another design consideration that needs to be combined with the design-flood level. However, most sea level projections do not have exceedance probabilities that can be used in conjunction with the design flood to obtain total flood elevations with exceedance probabilities. This paper shows how to combine design-flood elevations with sea level rise projections that have exceedance probabilities, such as those of the Intergovernmental Panel for Climate Change (Bindoff et al 2007) or Houston (2012a), to obtain total elevations at desired exceedance probabilities over particular intervals.
\end{abstract}

Keywords: sea level rise; coastal flooding

\section{INTRODUCTION}

There is a wide range of sea level forecasts to 2100. The Intergovernmental Panel on Climate Change (IPCC, Bindoff et al 2007) forecast an upper limit of sea level rise from 1990 to 2100 of $0.59 \mathrm{~m}$ at the 95\%-confidence level. Although it did not completely consider contributions from Greenland and Antarctica, it estimated that they could contribute -0.01 to $0.17 \mathrm{~m}$ to the upper limit. A survey by Nichols et al (2011) shows that recent projections of sea level rise by 2100 have typically been 1-2 m with Greenland and Antarctica being the greatest contributors. Differences between these projections and those of IPCC are typically attributed to IPCC not having fully having considered contributions from Greenland and Antarctica, even though differences generally are much greater than - 0.01 to 0.17 $\mathrm{m}$. However, these projections are not comparable to IPCC projections because they usually do not have exceedance probabilities and their upper limits are maximum possible rises, whereas IPCC projections have probabilities of exceedance.

Sea level rise projections with probabilities of exceedance are needed for project planning and design. Even nuclear power plant siting in the US considers exceedance probabilities rather than maximum possible events (Braverman et al, 2007). IPCC projections (Bindoff 2007) provide sea level rise with exceedance probabilities needed for planning and design, but they do not fully consider contributions from Greenland and Antarctica. This deficiency was addressed by (Houston 2012a), who applied IPCC methodology and the latest available data, including data from Greenland and Antarctica, to project sea level rise from 1990 to 2100 at 50\%-, and 95\%-confidence levels. Projections by Houston (2012a) are useful interim data until IPCC has new projections by 2013 to 2014 .

There have been few attempts to combine coastal design-flood levels with sea level projections with Heberger et al (2009) using the typical approach. They projected sea level rise to 2100 along the coast of California using methods of Rahmstorf (2007) that did not include exceedance probabilities. They added these projections directly to 100 -year coastal design-flood levels produced by phenomena other than sea level rise (e.g., storms, tides) and determined total combined water levels without exceedance probabilities. Tebaldi et al (2012) combined storm surge data and sea level projections with exceedance probabilities to project combined levels to 2030 and 2050. They showed that sea level rise would produce a significant increase in the frequency of extreme water levels. Hunter (2011) combined a coastal-flood elevation and projected sea level rise to determine a combined elevation such that the number of times it would be exceeded over a period by combined coastal flooding and sea level rise would be the same as the current elevation could be expected to be exceeded without consideration of sea level rise.

This paper combines flood levels (resulting from a combination of storm surge, tides, and other effects that temporarily raise local sea level) and sea level rise projections. Any coastal design-flood exceedance probability can be considered, however, since design-flood levels are often for the 100-year flood, the discussion and examples will be for the 100-year flood level. The 100-year coastal designflood level is assumed known and the need is to determine a total design water elevation that accounts for both coastal floods and sea level rise over an interval such as the project design life. A 100-year

\footnotetext{
${ }^{1}$ Engineer Research and Development Center, 3909 Halls Ferry Road, Vicksburg, MS, 39180, USA
} 
flood level has an annual $1 \%$ chance of being equaled or exceeded. Ninety-eight percent of values in a $98 \%$-confidence interval fall within the interval, $1 \%$ below the interval, and $1 \%$ above. Thus the $100-$ year flood level is the upper limit, designated $\mathrm{F}_{98 \%}$, of a $98 \%$-confidence interval centered on the mean flood level, designated $\mathrm{F}_{50 \%}$. Both $\mathrm{F}_{50 \%}$ and $\mathrm{F}_{98 \%}$ are assumed to be known and not time dependent.

\section{APPROACH}

Sea level projections for the year 2100 (with 1990 the base year of zero) are available from Bindoff (2007) or Houston (2012a). They provide mean projections, designated $\mathrm{SR}_{50 \%}$ (2100), and projections at the upper level of a 95\%-confidence interval, designated $\mathrm{SR}_{95 \%}$ (2100). The IPCC assumes its temperature and sea level rise projections are normally distributed. Therefore, $\mathrm{SR}_{95 \%}(2100)$ and $\mathrm{SR}_{50 \%}$ (2100) are known and normally distributed. The following summarizes the methodology presented in Houston (2012b).

For normal distributions, the probability, Q (z), that a level, z, will be equaled or exceeded equals $1-\mathrm{P}(\mathrm{z})$, where $\mathrm{P}(\mathrm{z})$ is the cumulative normal standard distribution function (total probability of 1 ) from $-\infty$ to $z$ (Patel and Reed, 1996) given by

$$
\mathrm{P}(\mathrm{z})=\frac{1}{\sqrt{2 \pi}} \int_{-\infty}^{z} e^{-t^{2} / 2} \mathrm{dt}
$$

Q (z) also can be expressed (Patel and Reed, 1996) as

$$
\mathrm{Q}(\mathrm{z})=1 / 2[1-\operatorname{erf}(\mathrm{z} / \sqrt{2})]
$$

where "erf" is the error function and is available as an intrinsic function in many computer codes (e.g., MATLAB).

A confidence interval is one in which a measurement or trial falls corresponding to a given probability. As is well known (Houston, 2012b) the width of the 95\%-confidence interval is $1.96 \sigma$. Similarly, the width of the $98 \%$-confidence interval is $2.33 \sigma$. Houston $(2012 b)$ shows

$$
\mathrm{SR}_{95 \%}(2100)-\mathrm{SR}_{50 \%}(2100)=1.96 \sigma
$$

Similarly,

$$
\mathrm{SR}_{98 \%}(2100)-\mathrm{SR}_{50 \%}(2100)=2.33 \sigma
$$

$\mathrm{SR}_{95 \%}$ (2100) must be converted to $\mathrm{SR}_{98 \%}$ (2100) to be consistent with the level of probability of the design flood being considered. Taking the ratio of Eqs 3 and 4,

$$
\mathrm{SR}_{98 \%}(2100)-\mathrm{SR}_{50 \%}(2100)=\left[\mathrm{SR}_{95 \%}(2100)-\mathrm{SR}_{50 \%}(2100)\right] * 2.33 / 1.96
$$

IPCC assumes that sea level rise follows a standard quadratic curve given by

$$
\operatorname{SR}(\mathrm{t})=\mathrm{a}_{0}+\mathrm{a}_{1} *(\mathrm{t}-1990)+1 / 2 \mathrm{a}_{2} *(\mathrm{t}-1990)^{2}
$$

where $t$ is the year, SR ( $t$ ) and $a_{0}$ units of $m, a_{1}$ of $\mathrm{m} / \mathrm{yr}$, and $\mathrm{a}_{2}$ of $\mathrm{m} / \mathrm{yr}^{2}$

Sea level rise projections are typically from 1990 to 2100 to compare with the first IPCC report that was published in 1990, and Bindoff et al (2007) and Houston (2012a) project $\mathrm{SR}_{95 \%}$ from 1990 to 2100. Houston (2012b) shows that given $\mathrm{SR}_{98 \%}(2100)$ and $\mathrm{SR}_{50 \%}(2100)$, a zero rise in the base year of 1990, a worldwide sea level trend of about $3 \mathrm{~mm} / \mathrm{yr}$ from late 1992 to 2012 measured by satellite altimeters, and the assumption used by IPCC and others that sea level follows a quadratic rise, $\mathrm{SR}_{98 \%}(\mathrm{t})$ and $\mathrm{SR}_{50 \%}(\mathrm{t})$ are known for all times from 1990 to 2100 .

$\mathrm{F}_{50 \%}$ and $\mathrm{F}_{98 \%}$ are assumed to be known as a part of project planning/design and may well have been determined by assuming a distribution other than a normal distribution. This paper uses an approach analogous to that used by the IPCC for sea level rise projections. The IPCC projects means and confidence levels from 1990 to 2100 for components sea level rise without reference to distributions. However, the IPCC then fits means and confidence levels of the components with normal distributions so that it can take advantage of the unique property of normal distributions that their means add directly and their errors add in quadrature with the final distribution being normal. This paper does the same with $\mathrm{F}_{50 \%}$ and $\mathrm{F}_{98 \%}$. They are kept unchanged from their project planning/design determination, but fit with a normal distribution so the mean can add directly to the mean of the sea level rise projection and errors can be added in quadrature. The IPCC indicates any resulting error is small compared to 
uncertainties in its sea level projections. In addition, IPCC's sea level projections are made without reference to coastal flooding from storms or other phenomena and, thus are independent of coastal flood projections.

Adding means,

$$
\mathrm{T}_{50 \%}(\mathrm{t})=\mathrm{F}_{50 \%}+\mathrm{SR}_{50 \%}(\mathrm{t})
$$

$\mathrm{F}_{50 \%}$ does not depend on $\mathrm{t}$, since for this example both $\mathrm{F}_{50 \%}$ and $\mathrm{F}_{98 \%}$ are fixed levels.

Adding error intervals in quadrature produces a total level at the $98 \%$-confidence level for each year, $\mathrm{T}_{98 \%}(\mathrm{t})$, as follows (for example, see Castrop, 2004):

$$
\mathrm{T}_{98 \%}(\mathrm{t})=\mathrm{T}_{50 \%}(\mathrm{t})+\mathrm{SQRT}\left[\left\{\mathrm{F}_{98 \%}-\mathrm{F}_{50 \%}\right\}^{2}+\left\{\mathrm{SR}_{98 \%}(\mathrm{t})-\mathrm{SR}_{50 \%}(\mathrm{t})\right\}^{2}\right]
$$

Therefore, for each year there is a total combined coastal flood and sea rise level, $\mathrm{T}_{98 \%}(\mathrm{t})$, which has an annual probability of $0.01(1 \%)$ of being equaled or exceeded.

Coastal design-flood level typically have a fixed annual probability of exceedance (e.g., $1 \%$ or 0.01), whereas Eq. 8 has total combined coastal flood and sea rise levels that increase each year. However, it is possible to obtain exceedance probabilities over particular time periods that match with those associated with the 100-year design elevation or any other design elevation. To do this, one selects an initial arbitrary total elevation of $\mathrm{T}_{\text {initial. }}$. This elevation will exceed elevations with 0.01 exceedance probabilities for early years of the interval and be less for later years. Similar to Eqs. 4 and 5 ,

$$
\begin{gathered}
\mathrm{T}_{\text {initial }}-\mathrm{T}_{50 \%}(\mathrm{t})=\mathrm{z}(\mathrm{t}) \sigma \\
\mathrm{T}_{98 \%}(\mathrm{t})-\mathrm{T}_{50 \%}(\mathrm{t})=2.33 \sigma
\end{gathered}
$$

Again, taking the ratio of Eqs. 9 and 10 and solving for $\mathrm{z}(\mathrm{t})$,

$$
\mathrm{z}(\mathrm{t})=2.33 *\left[\mathrm{~T}_{\text {initial }}-\mathrm{T}_{50 \%}(\mathrm{t})\right] /\left[\mathrm{T}_{98 \%}(\mathrm{t})-\mathrm{T}_{50 \%}(\mathrm{t})\right]
$$

Equation 11 can be solved for $\mathrm{z}(\mathrm{t})$ for each year, $\mathrm{t}$, since all other variables are known. From Eq. 2,

$$
\mathrm{Q}(\mathrm{t})=\mathrm{Q}(\mathrm{z}(\mathrm{t}))=1 / 2[1-\operatorname{erf}\{\mathrm{z}(\mathrm{t}) / \sqrt{2}\}]
$$

Equation 12 is then used to determine $\mathrm{Q}(\mathrm{t})$, the probability for each year, $t$, that $\mathrm{T}_{\text {initial }}$ will be equaled or exceeded. $P(t)=1-Q(t)$ is the probability for each year, $t$, that $T_{\text {initial }}$ will not be equaled or exceeded.

If one wants the total probability, $\Omega$, that the elevation, $T_{\text {initial }}$ is equaled or exceed over the 50 -year period from 2012 to 2062 ,

$$
\Omega=1-(\mathrm{P}(2012) * \mathrm{P}(2013) * \mathrm{P}(2014) * \ldots * \mathrm{P}(2062))
$$

Suppose the desire is to have $\Omega$ equal the probability of exceedance over a 50 -year period of an event that has an annual probability of 0.01 (probability of exceedance $=1-\{0.99\}^{50}=0.39$ ). If $\Omega$ determined from Eq. 13 is greater than 0.39 , then $\mathrm{T}_{\text {initial }}$ was too low an initial value, and it is increased in a second iteration. The reverse is the case if $\Omega$ is less than 0.39 . Iterating, one eventually obtains a total elevation such that $\Omega=0.39$. If one wants a different probability of exceedance over the time period, $T_{\text {initial }}$ is adjusted until $\Omega$ reaches the desired exceedance probability.

\section{EXAMPLES}

As an example, consider the total combined coastal flood and sea rise level that has a 0.39 chance of being equaled or exceeded in a 50-year period from 2012 to 2062 at Moturiki Island, Bay of Plenty, New Zealand. From Goring et al (2010), $\mathrm{F}_{50 \%}$ and $\mathrm{F}_{98 \%}$ for Moturiki Island are relatively small with approximate values of $0.2 \mathrm{~m}$ and $0.59 \mathrm{~m}$ respectively. From Houston (2012a), $\mathrm{SR}_{50 \%}$ (2100) and $\mathrm{SR}_{95 \%}$ (2100) for IPCC scenario A1F1 are $0.60 \mathrm{~m}$ and $0.82 \mathrm{~m}$ respectively. From Eq. 5, SR ${ }_{98 \%}(2100)=0.86$ $\mathrm{m}$.

Equation 6 determines $\mathrm{SR}_{98 \%}(\mathrm{t})$ and $\mathrm{SR}_{50 \%}(\mathrm{t})$ values for all years from 1990 to 2100 . Equations 9 and 10 provide $\mathrm{T}_{50 \%}$ and $\mathrm{T}_{98 \%}$ values for all years from 1990 to 2100 . Suppose a first guess for $\mathrm{T}_{\text {initial }}$ is $0.75 \mathrm{~m}$. Equation 11 is solved for each year to obtain $\mathrm{z}(\mathrm{t})$ values and then Eq. 12 to obtain $\mathrm{Q}(\mathrm{t})$ values. Equation 13 yields an initial value $\Omega=0.79$. Increasing $T_{\text {initial }}$ in steps eventually yields $\Omega=$ 
0.39 for a total elevation of $0.83 \mathrm{~m}$. The methodology is easily applied to obtain any desired probability of exceedance. For example, as seen in Fig. 1, a 15\% probability of exceedance from 2012 to 2062 would require a combined flood and sea level design elevation of about $0.9 \mathrm{~m}$.

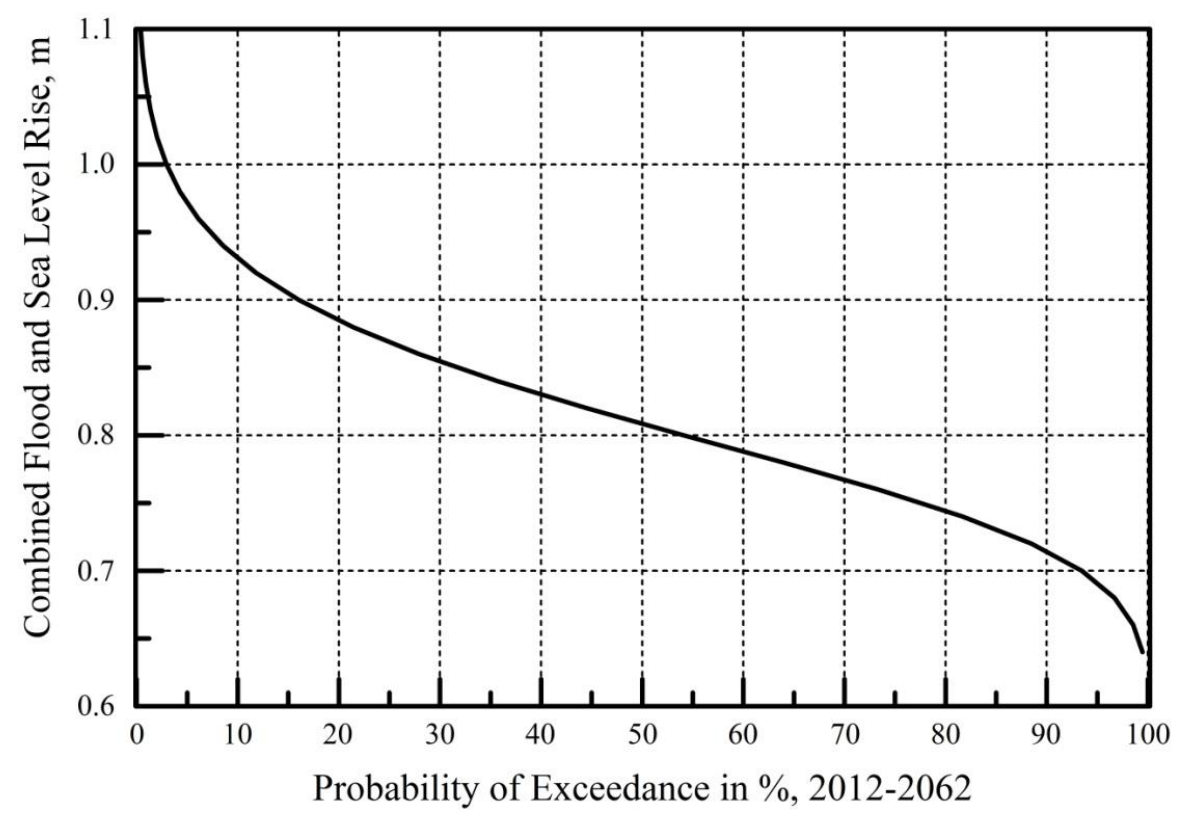

Figure 1. Combined flood and sea level rise versus probability of exceedance for Moturiki Island for the interval 20122062.

The combined flood and sea level rise for a particular year can be easily determined for the case where $\left\{\mathrm{F}_{98 \%}-\mathrm{F}_{50 \%}\right\}^{2}$ in Eq. 8 is much greater than $\left\{\mathrm{SR}_{98 \%}(\mathrm{t})-\mathrm{SR}_{50 \%}(\mathrm{t})\right\}^{2}$. Then from Eqs. 7 and 8 ,

$$
\mathrm{T}_{98 \%}(\mathrm{t})=\mathrm{F}_{98 \%}+\mathrm{SR}_{50 \%}(\mathrm{t})
$$

That is, the total flood plus sea level rise with a $1 \%$ chance of being equaled or exceeded equals the $1 \%$ flood level plus the $50 \%$ sea rise level.

Cuxhaven, Germany, is an example of a location where $\left\{\mathrm{F}_{98 \%}-\mathrm{F}_{50 \%}\right\}^{2}>\left\{\mathrm{SR}_{98 \%}(\mathrm{t})-\mathrm{SR}_{50 \%}\right\}^{2}$. From Jensen et al (2004), $\mathrm{F}_{50 \%}$ and $\mathrm{F}_{98 \%}$ are approximately $1.6 \mathrm{~m}$ and $3.9 \mathrm{~m}$ above mean high water respectively. $\left\{\mathrm{F}_{98 \%}-\mathrm{F}_{50 \%}\right\}^{2}$ is about $5.3 \mathrm{~m}^{2}$. From Houston $(2012 \mathrm{a}), \mathrm{SR}_{98 \%}(2100)=0.86 \mathrm{~m}$ and $\mathrm{SR}_{50 \%}(2100)=0.60$, so $\left\{\mathrm{SR}_{98 \%}(\mathrm{t})-\mathrm{SR}_{50 \%}(\mathrm{t})\right\}^{2}$ is about $0.07 \mathrm{~m}^{2}$. Fig. 2 shows combined flood and sea level rise as a function of exceedance probability for Cuxhaven, Germany, for 2012 - 2062. 


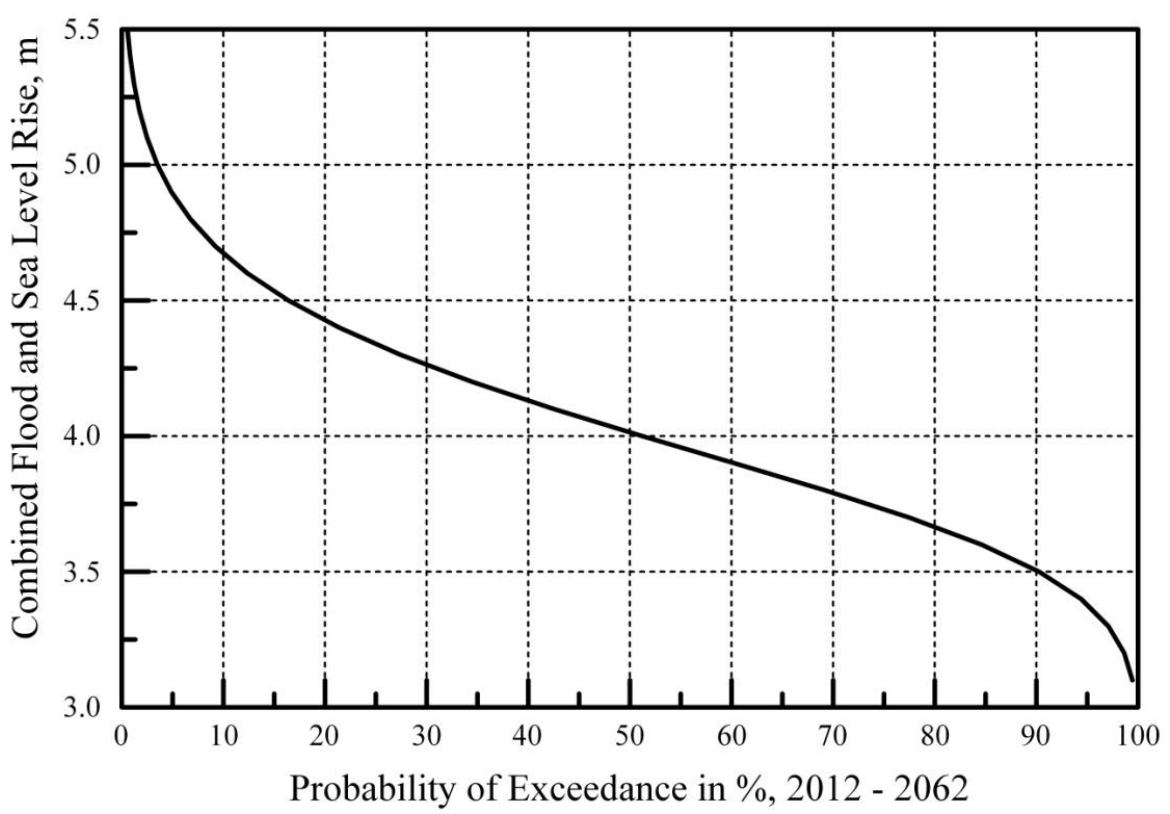

Figure 2. Combined flood and sea level rise versus probability of exceedance for Cuxhaven, Germany, 2012 to 2062

For locations where $\left\{\mathrm{F}_{98 \%}-\mathrm{F}_{50 \%}\right\}^{2}>\left\{\mathrm{SR}_{98 \%}(\mathrm{t})-\mathrm{SR}_{50 \%}\right\}^{2}, \mathrm{~F}_{50 \%}$ is no longer a variable, and the combined flood and sea level can be plotted as a function of probability of exceedance for various $\mathrm{F}_{98}$ elevations as shown in Fig. 3. As expected, the combined flood and sea level versus exceedance probabilities differ by approximately differences in $\mathrm{F}_{98}$ levels, although the differences widen for low exceedance probabilities and narrow for high exceedance probabilities.

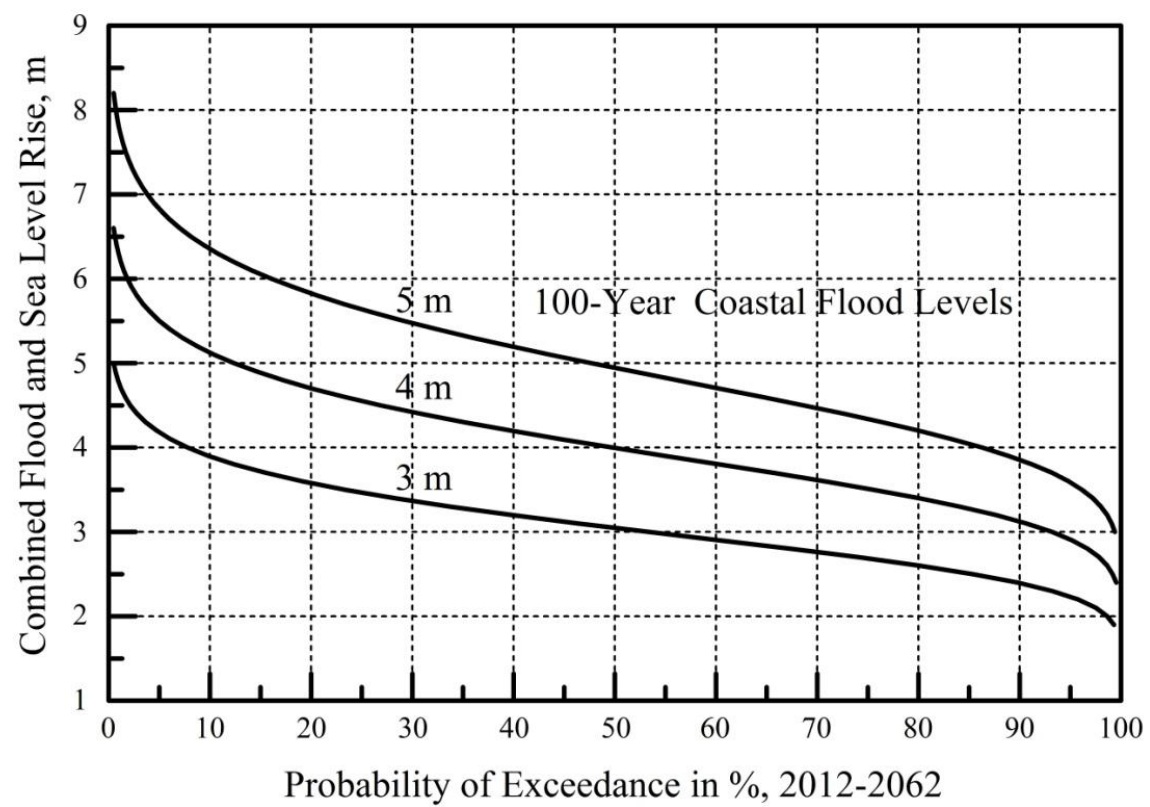

Figure 3. Combined flood and sea level rise versus probability of exceedance for various 100 -year coastal flood levels, 2012 to 2062

\section{SUMMARY AND CONCLUSIONS}

Project planning and design require sea level rise projections with associated exceedance probabilities to determine combined coastal flood-design elevations and sea level rise over project design intervals. Most available sea level projections do not have exceedance probabilities, and, therefore, projections such as those of Bindoff et al (2007) or Houston (2012a) must be used. A 
approach is presented to combine sea level rise projections that have exceedance probabilities with coastal flood-design levels to produce total combined water levels at desired exceedance probabilities over any time interval.

\section{ACKNOWLEDGEMENTS}

I very much appreciate the review provided by Professor Robert G. Dean and his stimulation of my interest in sea level rise and collaboration on earlier papers.

\section{REFERENCES}

Abramowitz, M. and I.A. Stegun, (eds). 1972. Handbook of Mathematical Functions with Formulas, Graphs, and Mathematical Tables, New York, Dover Publications, ISBN 978-0486-61272-0.

Bindoff, N.L., Willebrand, J., Artale, V., Cazenave, A., Gregory, J., Gulev, S., Hanawa, K., Le Que're', C., Levitus, S., Noijiri, Y., Shum, C.K., Talley, L.D., and A. Unnikrishnan, A. 2007. Observations: oceanic climate change and sea level, In: Solomon, S., et al. (eds.), Climate Change 2007: The Physical Science Basis, Intergovernmental Panel on Climate Change, Cambridge University Press, 385-432.

Braverman, J.I., Xu1, J., Ellingwood B.R., Costantino, C.J., Morante R.J., and C.H. Hofmayer. 2007. Evaluation of the seismic design criteria in ASCE/SEI Standard 43-05 for application to nuclear power plants, NUREG/CR-6926, available online at http://www.nrc.gov/reading$\mathrm{rm} /$ doc-collections/nuregs/contract/cr6926/cr6926.pdf.

Castrop, H. 2004. Estimating and combining uncertainties, 8th Annual International Test And Evaluation Association Instrumentation Workshop, available online at: http://www.isgmax.com/Articles_Papers/Estimating\%20and\%20Combining\%20 Uncertainties.pdf.

Goring, G.G., Stephens, S.A., Bell, R.G., and C.P. Pearson. 2011. Estimation of extreme sea levels in a tide-dominated environment using short data records, Journal, Waterway, Port, Coastal, Ocean Engineering. American Society of Civil Engineers, 137, 150-159.

Heberger, M., Cooley, H., Herrera, P., Gleick, P.H., and E. Moore. 2009. The impacts of sealevel rise on the California coast, California Energy Commission Report No. CEC500-2009-024-F, available online at: http://www.pacinst.org/reports/sea_level_rise/report.pdf.

Houston. J.H. 2012a. Sea level projections to 2100 using methodology of the Intergovernmental Panel on Climate Change, Special Issue, Journal of Waterway, Port, Coastal, and Ocean Engineering, American Society of Civil Engineering (in publication).

Houston J.H. 2012b. Methodology for Combining Coastal Design-Flood Elevations and Sea Level Rise Projections, Journal of Waterway, Port, Coastal, and Ocean Engineering, American Society of Civil Engineering (submitted).

Hunter, J. 2011. "A simple technique for estimating an allowance for uncertain sea-level rise." Climate Change, doi: 10.1007/s10584-011-0332-1, available online at http://rd.springer.com/article/10.1007/s10584-011-0332-1.

Jensen, J., Mudersbach, C., Koziar, C., and Bork, I., (2004), “ Modelling of extreme storm surge weather situations in the North Sea and its statistical analysis." Proceedings of Littoral 2004, 2, 438-443, available online at http://www.abdn.ac.uk/cmczm/littoral2004_proceedings.htm

Nicholls. R.J., Marinova, N., Lowe, J.A., Brown, S., Vellinga, P., de Gusmao, D., Hinkel, J., Tol, R.S.J. (2011). "Sea-level rise and its possible impacts given a 'beyond $4^{\circ} \mathrm{C}$ world' in the twenty-first century." Philosophical Transactions of the Royal Society, 369 (1934), 161-181, doi: 10.1098/rsta.2010.0291.

Patel, J. K. and Reed, C.B., 1996, "Handbook of the normal distribution." $2^{\text {nd }}$ Edition, CRC Press, 456 p, ISBN-10: 0824793420.

Rahmstorf, S. (2007). “A semi-empirical approach to projecting future sea-level rise.” Science, $315,368-370$.

Tebaldi, C., Strauss. B. H., and Zervas, C.E. (2012). "Modeling sea level rise impacts on storm surges along US coasts." Environmental Research Letters. 7 (1), doi:10.1088/17489326/7/1/014032, available online at: http://iopscience.iop.org/1748- 